\title{
Pendidikan Spiritual Dalam Tradisi Istighosah Santri Pondok Pesantren AL Mahrusiyah III Ngampel Kota Kediri
}

\author{
${ }^{1}$ Fuad Hasim, ${ }^{2}$ Yasin Nur Falach \\ ${ }^{1}$ Institut Agama Islam Tribakti Kediri, ${ }^{1}$ Institut Agama Islam Tribakti Kediri \\ 1 fuadhasim1986@gmail.com, 22yesnurfalah@gmail.com
}

\begin{abstract}
This research was conducted to determine how spiritual education is in the istighotsah tradition of HM Al-Mahrusiyah III Ngampel Islamic boarding schools. Spiritual education is education that instills a sense of love for Allah in a person's heart which makes him expect Allah's blessing, both in every word, deed, attitude and behavior. Itighotsah is an expectation of help from Allah, because Allah is the most helper of everything and only Allah who grants all kinds of human needs that become their wants and needs. In this study, the authors used a descriptive qualitative approach which moved from two questions, namely; 1) How is the process of Istighotsah activity 2) How is the spiritual change felt after attending Istighotsah. With the questions that formulated the problem, the researcher obtained the following results: 1) The pre-istighotsah stage, carried out for operation. The istighotsah stage, there are three parts in it, the first is Muqodimah, namely the Tasbih, Witir and Hajat circumcision prayers. Second Contents, namely tawashul, tahlil and reciting dhikr. Third Closing, read Hisbus Salamah, Hisbun Nasar and prayer istighotsah. Post istighotsah stage. Carry out the subuh prayer in congregation. 2) calms the soul, because in it there are things that bring calm, such as circumcision prayer, dzikrullah in reciting tahlil, tahmit, tasbih, takbir and sholawat.
\end{abstract}

Key Word: Spiritual, Tradition, Istighotsah.

\begin{abstract}
Abstrak
Penelitian ini dilakukan untuk mengetahui bagaimana pendidikan spiritual dalam tradisi istighotsah santri Pondok Pesantren HM Al-Mahrusiyah III Ngampel. Pendidikan spiritual merupakan pendidikan yang menanamkan rasa cinta kepada Alloh di dalam hati seseorang yang menjadikannya mengharap ridho Alloh, baik di setiap ucapan, perbuatan, sikap dan tingkah laku. Itighotsah merupakan pengharapan adanya pertolongan dari Alloh, karena Alloh lah yang maha penolong segalanya dan hanya Alloh yang maha mengabulkan atas segala macam kebutuhan manusia yang menjadi keinginan serta kebutuhannya. Pada penelitian ini penulis menggunakan pendekatan kualitatif diskriptif yang beranjak ari dua pertanyaan, yaitu; 1) Bagaimana Proses Kegiatan Istighotsah 2) Bagaimana Perubahan Spiritual yang Dirasakan Setelah Mengikuti Istighotsah. Dengan adanya pertanyaan yang menjadi rumusan masalah tersebut, peneliti mem-peroleh hasil sebagai berikut: 1) Tahap pra istighotsah, dilakukan pengoprakan. Tahap istighotsah, ada tiga bagian didalamnya, pertama Muqodimah, yaitu sholat sunat Tasbih, Witir dan Hajat. Kedua Isi, yaitu tawashul, tahlil dan membaca dzikir. Ketiga Penutup,


Pendidikan Spiritual Dalam Tradisi Istighosah Santri Pondok Pesantren AL Mahrusiyah III N Ngampel. . Oleh: Fuad Hasim Dan Yasin Nurfalach

membaca Hisbus Salamah, Hisbun Nasar dan do'a istighotsah. Tahapan pasca istighotsah. Melaksanakan sholat subuh berjama'ah. 2) menenangkan jiwa, karena di dalamnya terdapat hal-hal yang mendatangkan ketenangan, seperti sholat sunat, dzikrullah dalam pembacaan tahlil, tahmit, tasbih, takbir dan sholawat.

Kata Kunci: Pendidikan Spiritual, Tradisi, Istighotsah.

\section{Pendahuluan}

Seiring dengan berkembangnya zaman, ilmu pengetahuan dan teknologi juga mengalami perkembangan yang begitu pesat. Perkembangan ini sangat memberikan manfaat bagi kehidupan manusia. Namun disisi lain perkembangan ilmu pengetahuan dan teknologi juga memberikan dampak yang negatif bagi kehidupan manusia. Manusia mulai meninggalkan spiritualitas yang mengakibatkan krisis spiritual dengan ditunjukan menurunnya akhlak manusia. ${ }^{1}$

Dalam kondisi seperti inilah manusia sangat perlu yang namanya pendidikan spiritual guna menuntun dalam menjalani gejolak problematika kehidupan sosial di zaman modern. Manusia membutuhkan ajaran agama yang mampu memenuhi kehausan ruhaniyahnya agar menjadikan penyejuk bagi jiwa dan pikirannya supaya setiap perilaku tetap dalam garis Ilahi yang dikenal dengan spiritualitas. Spiritualitas merupakan sebuah kata dari kata spirit yang berarti roh, kata ini juga berasal dari kata "spiritus" yang berarti bernafas. Dengan demikian, spiritual bisa diartikan se- bagai roh dan nafas yang berfungsi sebagai energi kehidupan yang membuat seseorang menjadi hidup. Meravigliya menjelaskan dua dimensi spiritual yang mencerminkan pada nilai-nilai utama, yakni dimensi vertikal yang menghubungkan seseorang dengan tuhan dan dimensi horizontal yang berhubungan dengan alam. ${ }^{2}$

Keadaan zaman yang berkembang seperti saat ini, manusia membutuhkan bimbingan untuk mengembangkan segala potensi yang dimiliki setiap individu, baik dari segi emosionalnya, intelektualnya dan dari segi spiritualnya. ${ }^{3}$ Kecerdasan Intelektual yang digunakan untuk menyelesaikan permasalahan matematika logis setiap individu dari aspek kognitiv, kecerdasan emosional yang digunakan untuk menyelesaikan permaslahan yang berkaitan dengan emosi dan kaitannya dengan pengendalian diri yang berhubungan antar sesama manusia, kecerdasan spiritual digunakan untuk menemukan sebuah makna yang terkandung dalam men-

Qodhi Abi Saidil Mahzumi and A. Jauhar Fuad, "Spiritual Education Through Ziarah Tradition In Syaikh Syamsuddin Al-Wasil Town Kediri City," EL HARAKAH Jurnal Budaya Islam 21, no. 2 (December 3, 2019): 237-54, https://doi.org/10.18860/el.v21i2.7030

Yuliyatun, "Mengembangkan Kecerdasan Spiritual Anak Melalui Pendidikan Agama", jurnal dakwah STAIN Kudus, Vol.1, No. 1 (Desember, 2013), h. 155.

el Bidayah: Journal of Islamic Elementary Education Volume 2, Nomor 2, September 2020 
jalani kehidupan. ${ }^{4}$ Dari ketiga kecerdasan tersebut membentuk kecerdasan hierarkhi yang tidak dapat dipisahkan dan harus dimiliki setiap insan manusia. $^{5}$

Harus diakui pula secara realita bahwa sekarang telah terjadi pergeseran dimensi material dan spiritual. Dimana dimensi material atau kebendaan telah menjadi kebutuhan primer, sedangkan dimensi spiritual telah menjadi kebutuhan sekunder. Untuk itu nilai spiritual memegang peran yang sangat penting bagi perilaku kita di zaman modern sperti sekarang ini. Pendidikan spiritual merupakan benteng utama bagi penguasaan nafsu dan emosi. Jika benteng pertahanan itu rapuh maka hilanglah keseimbangan mental diri seseorang. Dalam keadaan seperti inilah seseorang dengan mudah melakukan tindakan tidak terpuji bahkan perilaku yang tidak manusiawi seperti pembunuhan, penganiayaan, korupsi dan lain sebagainya. ${ }^{6}$

Fuat Fauzi mengatakan, tujuan dari pendidikan spiritual ini ialah peralihan dari sudut pandang pribadi yang sempit ke sudut pandang yang luas yaitu Ilahi. Secara sederhana keberadaan ma-

\footnotetext{
4 Ahmad Nur Said, Pengaruh Kecerdasan Spiritual Intelektual Dan Kecerdasan Spiritual Terhadap Sikap Etis Mahasiswa, Journal of Universitas Negri Yogyakarta, Vol. VII, No. 1, (2018), h. 26.

5. Yasin Nur Falah, "Pengaruh Kecerdasan Intelektual Dengan Kecerdasan Emosional", Jurnal Tribakti, Vol. 26, No. 2 (2016).

6 Aninda Umi Nur Arifah, Hubungan Antara Kecerdasa Spiritual Dengan Prilaku Prososional Pada Remaja, (Desember, 2018), h. 3.

7 Fuat Fauzi, "Pendidikan Spiritual Dalam Mengembangkan Karakter Perspektif el Bidayah: Journal of Islamic Elementary Education Volume 2, Nomor 2, September 2020
}

nusia terdiri dari dua kutub kesadaran yaitu, kesadaran individu yang berarti bersifat pribadi, dan kesadaran Ilahi. ${ }^{7}$ Imam al-Ghozali beranggapan tujuan $\mathrm{u}$ mum pendidikan spiritual ialah menciptakan insan manusia agar berusaha mendekatkan diri kepada Alloh. ${ }^{8}$

Dr. Abdul Munir Mulkhan berpendapat bahwa pendidikan spiritual dikenal sebagai pendidikan kepribadian yang didasarkan kepada kecerdasan emosional dan spiritual yang bertumpu pada permasalah self atau diri. Keseimbangan menggunakan kecerdasan emosional dan spiritual akan menciptakan insan kamil, sekaligus mampu menjadi umat yang memiliki kesalehan dari segi individu dan kesalehan dari segi sosial. ${ }^{9}$

Lembaga pondok pesantren yang merupakan bagian dari masyarakat yang hidup di tengah perkembangan zaman juga tidak lepas dari permasalahan yang berkaitan dengan spiritual yang dialami masyarakat pada umumnya. ${ }^{10}$ Pesantren merupakan basic pertahanan ajaran-ajaran Islam, namun realitanya sekarang mulai bergeser di kalangan santri hususnya para remaja. Pergeseran ini kecenderungan mereka mengikuti

Imam Al-Gozali", (Skripsi, Universitas Negri Sunan Kalijaga, Yogyakarta, 2015), h. 4.

8 Muhamad Akhmansyah, "Eksistensi Guru Dalam Pendidikan Spiritual Perspektif Abu Hamid Al-Ghozali", Al-Tazkiyyah: Jurnal Pendidikan Islam, Vol. 6 (November, 2015), h. 311.

9 Pengertian Pendidikan Spiritual, http://www.jejakpendidikan.com/2016/12/pe ngertian-pendidikan-spiritual.html, diakses tanggal 10 Januari 2020.

10 Rustam Ibrahim, "Pesantren dan Pengabdian Masyarakat", Jurnal At-Tahrir, Vol. 16, No. 1 (Mei, 2016), h. 92. 
budaya luar, yang tak sejalan dengan prinsip pesantren. Pelanggaran-pelanggaran atau perilaku negatif santri kerap bermuara pada budaya tersebut, seperti halnya melihat konser musik, kekerasan fisik, pencurian, pacaran, bahkan minum minuman keras (miras), tetapi itupun tidak semua santri melakukan seperti itu dan hanya segelintir dari santri. Selain itu, permasalahan yang sering dialami oleh santri ialah keluar pondok tanpa izin, membolos sekolah formal maupun Diniyah, tidak sholat ber jama'ah, mudah putus asa, acuh tak acuh yang disertai sikap menentang kepada pengurus merupakan masalah yang sering melanda santri di lembaga pondok pesantren. ${ }^{11}$

Untuk mengatasi persoalan yang dialami santri di atas, Pondok Pesantren Lirboyo HM Al Mahrusiyah III Ngampel mempunyai upaya pembinaan yang menitik beratkan pada pendidikan spiritual. Karena dalam kehidupan tidak hanya dibutuhkan cerdas intelektual saja, akan tetapi juga dibutuhkan cerdas spirit untuk berketuhanan guna menyadari bahwa dalam kehidupan ada yang selalu melihat, yaitu Alloh SWT. Kita juga harus sadar bahwa setiap keberhasilan yang di dapatkan tidak lain atas kehendaknya, sehingga seyogyanya kita sebagai mahluknya slalu berdo'a memohon kepada Alloh, hal ini merupakan perwujudan dari pendidikan spiritual.

11 Sayidul Ayyam, Wawancara, Pondok Pesantren Al-Mahrusiyah III Ngampel, 20 Desember 2019.

12 Ibrohim, Wawancara, Pondok Pesantren Al-Mahrusiyah III, 20 Desember 2019.

13 Ibnu Solahudin, Wawancara, Pengurus Pondok Pesantren Al-Mahrusiyah III Ngampel, 2 Januari 2020.

92
Dan yang harus diketahui bahwa setiap pencapaian yang di dapat pasti slalu diiringi dengan usaha. Dengan demikian, pendidikan spiritual yang dilalukan di pondok Pesantren Al-Mahrusiyah ini dengan mewajibkan semua santri untuk mengikuti kegiatan Istighotsah. Kegiatan Istighotsah yang dilakukan santri Pondok Pesantren Lirboyo HM AlMahrusiyah III Ngampel dimulai pada jam 02.30 WIB. Kegiatan ini wajib diikuti oleh semua santri setiap hari. ${ }^{12}$

Tradisi istighotsah merupakan salah satu kegiatan santri Pondok Pesantren HM. Al-Mahrusiyah III Ngampel yang berhubungan dengan pendidikan spiritual. Menurut salah satu pengurus beranggapan bahwa Istighotsah merupakan rangkaian kegiatan yang di dalamnya mengandung unsur pendidikan spiritual. ${ }^{13}$ Adapun susunan tradisi istighosah seperti, sholat sunat tasbih, witir, hajat, membaca tahlil, membaca surat yasin, solawat, dzikir, pembacaan hizib dan rankaian do'a memohon kepada Alloh. ${ }^{14}$

Kegiatan istighotsah yang di sakralkan Pondok Pesantren Al-Mahrusiyah ini menjadikan penulis beranggapan bahwa tradisi istighotsah ini dapat menjadikan metode santri dalam pendidikan spiritual agar menjadikan santri lebih semangat dalam berketuhanan dan mengikuti kegiatan di pondok pesantren sekaligus dalam menjalani kehi-

14 Almunjiat, Buku ini merupakan pedoman bagi santri Al-Mahrusiyah yang didalamnya terdapat bacaan-bacaar yang diamalkan ketika melakukan kegiatan santri setiap hari, salah satunya Istighotsah. 
dupan di era modern sekerang ini. Penelitian ini akan menjawab rumusan masalah sebagai berikut: (1) Bagaimana proses pelaksanaan istighotsah di Pondok Pesantren HM Al-Mahrusiyah III Ngampel? (2) Bagaimana dampak perubahan spiritual yang dirasakan setelah melakukan istighotsah?

\section{Metode}

Penelitian ini menggunakan penelitian kualitatif deskriptif. Penelitian ini ditujukan untuk menghasilkan suatu uraian mendalam tentang ucapan, tulisan yang berkaitan dengan yang akan di amati. Selain itu, dengan menggunakan penelitian kualitatif diharapkan mampu memberikan suatu penjelasan secara terperinci tentang fenomena yang terjadi. ${ }^{15}$ Penelitian kualitatif, merupakan penelitian yang ditujukan untuk mendeskripsikan dan menganalisis fenomena, peristiwa sikap, aktivitas sosial, kepercayaan, persepsi, pemikiran orang secara individu maupun kelompok. ${ }^{16}$

Penelitian kualitatif adalah salah satu metode penelitian yang bertujuan untuk mendapatkan pemahaman tentang kenyataan melalui proses berpikir secara induktif. ${ }^{17}$ Dalam hal ini, peneliti terlibat secara langsung dalam situasi dan kondisi yang diteliti. Dengan hal ini, peneliti dapat mengenali subjek yang akan diteliti dan mungkin bisa merasakan apa yang mereka alami

\section{Temuan dan Pembahasan}

15 Suko Susilo, Metode Penelitian Kualitatif (Surabaya: Jenggala Pustaka Utama, 2013), h. 9.
Sejarah yang telah disampaikan oleh $\mathrm{KH}$ Reza Ahmad zahid LC MA, Beliau adalah Putra dari pengasuh salah satu pengasuh Pondok Pesantren Lirboyo dan sekaligus pendidiri Pondok Pesantren Mahrusiyah Lirboyo Kota Kediri. PP Pesantren Mahrusiyah berawal dari Pondok Pesantren Lirboyo Kota Kediri. Bermula dari mbah manaf (Mbah Abdul Karim) yang aslinya dari Magelang, beliau ditinggal ayahnya. Kemudian beliau diasuh ayah tirinya dan resah akan situasi dan kondisiyang begitu-begitu saja. Mbah manaf memutuskan untuk mondok dengan usia yang tak memungkinkan karena dengan posisi sudah berumur. Beliau mondok di KH. Kholil Bangkalan dan akhirnya di pek mantu (dijadikan menantu) oleh mbah Sholeh Banjarmelati yang kemudian disuruh mengembangkan pondok di Desa Lirboyo dengan menantu-menantunya. Dari sejarah itulah pondok pesantren Lirboyo mempunyai kontribusi besar terhadap desa Lirboyo dalam segi infrastruktur dan suprastruktur .Pendidikan pondok Pesantren berbeda dengan pendidikan formalnnya. Orientasi pendidikan di luar hanya sebatas transform ilmu-ilmu yang diketahui guru untuk muridnya. Sementara di Pendidikan Pesantren tidak cukup dalam proses Ta'lim (pengajaran) saja. Tetapi juga ada Tarbiyah yaitu pembinaan dan pengarahan bagi pembentukan kepribadian dan sikap mental dan memperhatikan Ta'dib (pembentukan

16 Nana Sayaodih Sukmadinata, "Metode Penelitian Pendidikan", (Bandung, Remaja Rosdakarya, 2005), h. 60.

17 Susilo, Metode Penelitian Kualitatif, h. 
Karakter), kemandirian, kedisiplinan. Di Pondok Pesantren Lirboyo dengan tradisinya kental akan Adab dengan seorang guru sehingga tunduk karena rasa ta'dim kepada sosok seorang guru. Selain itu seorang santri dibiasakan sehingga terbiasa dengan agenda yang ada dipondok seperti: Sholat Hajat, Witir dan Tahajud, Istighosah, Jamaah Sholat Fardhu, Manaqib Syech Abdul Qodir Jailani, Pembacaan Surat Munjiat, Pembacaan Ratibul Hadad, Hizbul Jauzan, Sholawat Diba' \& Simtudurror. Dengan adanya kegiatan di atas spiritual seorang santri juga akan membuat hati santri Futuh (terbuka) jadi dalam menerima ilmu akan mudah dan dapat mengamalkannya. Dari tradesinya yang kental tersebut santri pondok pesantren Lirboyo juga akan ramah, beradab ketika diarahkan keluar, kearah sosial masyarakat sekitar. Dalam konteks inilah, Pondok Pesantren Mahrusiyah menyelenggarakan pendidikan spiritual.

Istighotsah merupakan sebuah kegiatan yang biasa dilakukan di lingkungan Pondok Pesantren. Hampir seluruh Pondok Pesantren di Indonesia melakukan kegiatan tersebut. Istighotsah merupakan rangkaian kegiatan yang sama halnya dengan berdo'a, akan tetapi konotasinya lebih dari sekedar berdo'a. Selaras dengan yang diungkapkan oleh pengasuh Pondok Pesantren HM AlMahrusiyah III Ngampel, beliau KH. Melvin Zainul Asyiqien bahwasanya istigho-

18 Melvin Zainul Asyiqien, Wawancaran, Rumah, Pondok Pesantren HM Al-Mahrusiyah III Ngampel, 13 Juli 2020, 23.51 WIB.

${ }^{19}$ A. Jauhar Fuad, "Tlatah Dan Tradisi Keagamaan Islam Mataraman," Jurnal 94 tsah merupakan istilah lain dari qiyamul lail yang banyak sekali manfaat yang terkandung didalamnya. Kalo dilihat dari sisi agama istighotsah merupakan kegiatan yang dianjurkan oleh syari'at Islam, besarsekali pahalanya bagi orang yang ber istighotsah. Selain itu, istighotsah juga sebagai sarana dalam do'a atau dzikir-dzikir kepada Alloh. ${ }^{18}$

Istighotsah sendiri berarti meminta pertolongan kepada Alloh lewat beberapa bacaan wirid-wirid di dalamnya. Di lingkungan Masyarakat maupun pondok pesantren istighotsah mempunyai nilai-nilai penting, karena dalam kegiatan istighotsah terdapat do'a, pertolongan, dan dzikir sebagai salah satu media mendekatkan diri kepada Alloh SWT. ${ }^{19}$ Istighosah merupakan kumpulan doa-doa yang dibaca dengan menghubungkan diri pribadi kepada Tuhan yang berisikan kehendak dan permohonan kepada-Nya serta di dalamnya diminta bantuan tokoh-tokoh populer dalam amal sholeh. Hampir seluruh pondok pesantren di Indonesia melakukan kegiatan tersebut. Istighosah merupakan rangkaian kegiatan yang sama halnya dengan berdo'a, akan tetapi konotasinya lebih dari sekedar berdo'a. Istighosah sendiri berarti meminta pertolongan kepada Alloh lewat beberapa bacaan wirid-wirid didalamnya. Di lingkungan Masyarakat maupun pondok pesantren istighosah mempunyai nilai-nilai penting, karena dalam kegiatan istighosah terdapat do'a, pertolongan, dan dzikir

Pemikiran Keislaman 30, no. 1 (January 31, 2019): 1-27,

https://doi.org/10.33367/tribakti.v30i1.659 
sebagai salah satu media mendekatkan diri kepada Alloh SWT. Salah satunya istighotsah yang dilakukan di Pondok Pesantren HM Al-Mahrusiyah III Ngampel.

Awal mula kenapa istighotsah dilakukan di Pondok pesantren $\mathrm{HM} \mathrm{Al-}$ Mahrusiyah sendiri itu ketika beliau KH. Imam Yahya Mahrus masih menimba Ilmu atau masih belajar sering kali melihat aktifitas ke istiqomahan beliau KH. Mahrus Aly yang merupakan Ayah beliau KH. Imam Yahya Mahrus yang selalu qiyamul lail atau ber istighotsah. Selain itu, KH. Imam Yahya Mahrus merupakan figur yang selalu qiyamyl lail, sehingga kebiasaan baik beliau ini ditularkan kepada anak-anak beliau dan juga anak-anak didik beliau.

Di samping itu, dengan mewajibkan santri-santri untuk mengikuti istighotsah agar supaya santri bisa terbiasa dengan yang namanya qiyamul lail dan juga menjadi bekal kelak ketika sudah pindah kamar (boyong) bisa menjalankan qiyamul lail atau beristighotsah dengan istiqomah.

Istighotsah yang dilakukan di Pondok Pesantren HM Al-Mahrusiyah III Ngampel mulai jam 02.30 WIB. Sebelum melaksanakan istighotsah, pengurus pondok mengkoordinir santri untuk bergegas menuju ke masjid. Pengurus pondok berkeliling untuk membangunkan santri yang masih tidur. Selain itu, pengurus pondok juga membagi tugas pada teman-teman santri untuk mengoprak secara bersama-sama, khususnya pada santri kelas tiga tingkatan SMK. Cara ini dilakukan agar kegiatan istightsah bisa berjalan dengan kondusi. Sebab jika tanpa adanya pengoprakan, maka ada sebagian santri yang tertidur ketika jam istighotsah dan kadang juga ada sebagian santri yang memang sengaja untuk tidak mengikuti istighotsah, cara ini dilakukan agar semua santri mengikuti istighotsah dan kegiatan istighotsah bisa berjalan dengan baik.

Selanjutnya yang dilakukan pengurus ialah dengan mengontrol santrisantri yang ada di Masjid untuk menyuruh teman-teman santri untuk segera bergegas mengambil air wudhu dan bergegas untuk bersiap-siap untuk mengikuti istighotsah.

Setelah semua-santri berada di Masjid, pengurus mengabsen santri untuk mengetahui siapa yang tidak mengikuti istighotsah sembari menunggu imam istighotsah yang biasanya dipimpin oleh pengasuh pondok. Terkadang pengurus juga kebagian untuk mengimami, hal tersebut dikarenakan pengasuh pondok biasanya sedang berada diluar kota ata sedang ada udzur.

Setelah imam istighotsah siap, maka semua santri yang mengikuti istighotsah disuruh mengikuti imam untuk melaksanakan beberapa rangkaian sholat sunat dan bacaan-bacaan istighotsah yang sudah tersusun dalam kitab Sab'ul Munjiat.

Istighotsah diawali dengan melakukan sholat sunat Tasbih sebanyak empat roka'at dengan dua kali salam. Setelah selesai sholat Tasbih, kemudian dilanjutkan dengan sholat sunat Witir sebanyak tiga raka'at dengan dua kali salam.

Ada perbedaan muqodimah istighotsah yang dilakukan pada malam senin, yaitu dengan melaksanakan sholat sunat witir tiga roka'at dengan dua 
Pendidikan Spiritual Dalam Tradisi Istighosah Santri Pondoß Pesantren AL Mahrusiyah III N Ngampel. . Oleh: Fuad Hasim Dan Yasin Nurfalach

kali salam, dilanjutkan sholat sunat hajat sebanyak empat roka'at dengan satu kali salam. Bacaan yang dilakukan ketika melaksanakan sholat sunat hajat pada roka'at pertama setelah membaca surah al-Fatihah membaca surah al-Ikhlas sebanyak 10x. Diteruskan roka'at kedua setelah membaca al-Fatihah membaca surah al-Ikhlas sebanyak 20x, roka'at ke-tiga setelah membaca surah al-Fatihah membaca surah al-Ikhlas sebanyak 30x dan pada roka'at ke-empat setelah membaca surah al-Fatihah membaca surah al-Ikhlas sebanyak 40x.

Setelah selesai melakukan sholat sunat Hajat, imam istighotsah memimpin jama'ah istighotsah untuk membaca surah al-Ikhlas sebanyak 71x, kemudian membaca Sholawat sebanyak 71x, kemudian membaca do'a istighfar meminta ampunan sebanyak $71 \mathrm{x}$ dan membaca surah al-Fatihah sebanyak 71x. Demikian muqodimah istighotsah yang dilakukan pada malam senin. Selanjutnya bacaan yang dibaca sama seperti malam-malam lainnya. Setelah selasai melaksanakan sholat sunat, dilanjutkan dengan membaca beberapa Sholawat, diantaranya Sholawat Fatih, Sholawat Munjiat, Sholawat Nariyah, Sholawat Tibbil Qulub.

Kemudian dilanjutkan dengan melaksanakan shalat sunnah Hajat sebanyak dua raka'at. Pada raka'at pertama setelah membaca surah al-Fatihah membaca surah al-Kafirun sebanyak 10x, diteruskan raka'at kedua setelah membaca surah al-Fatihah membaca surah al-Ikhlas sebanyak 10x. Setelah selesai melaksanakan sholat Hajat, imam memimpin jamaah untuk sujud. Adapun bacaan ketika sujud ialag de-ngan mem- baca Slolawat 10 kali, Hamdalah $10 \mathrm{kali}$ dan membaca do'a sapu jagat 10 kali.

Bagian selanjutnya yaitu imam istighotsah memimpin dengan bertawasul. Tawasul yang dilakukan disini mungkin sama dengan yang dilakukan oleh umat Islam pada umumnya, yaitu dengan menghadiahkan surah alFatihah kepada Nabi Muhammad SAW beserta keluarganya, para sahabat, Tabi'in dan umatnya, pada ulama dan orang-orang yang dikhususkan. Bacaan yang dilakukan selanjutnya ialah membaca Surah Yasin dilanjutkan dengan membaca tahlil secara bersama-sama. Setelah selesai membaca tahlil, dilanjutkan membaca bacaan sebagai berikut:

Selanjutnya ialah dengan membaca Hisbussalamah, Hisbunnasar lilistighotsah, kemudian Do'a fil Istighotsah, yang semua sudah ada di dalam kitab Sab'ul Munjiat, susunan beliau KH. Imam Yahya Mahrus. Ketika membaca Hisbussalamah, Hisbunnasar lilistighotsah, semua santri yang mengikuti istighotsah tersebut membaca secara bersamasama dengan melihat buku Sab'ul Munjiat. Sedangkan ketika membaca Do'a istighotsah, semua santri yang mengikuti istighotsah mengangkat tangan sembari mengamini bacaan Do'a yang dipimpin oleh imam istighotsah. Setelah selesai pembacaan do'a, semua santri serentak membaca:

Bacaan tersebut merupakan bagian akhir dalam kegiatan istighotsah yang dilakukan di Pondok Pesantren HM Al-Mahrusiyah III Ngampel.

Setelah selesai istighotsah, Мuadzin mengumandangkan Adzan Shubuh. Pengurus mengkoordinir teman-teman 
santri untuk mengambil air wudhu bagi yang sudah batal wudhunya. Sambil menunggu semua santri siap untuk mengikuti Sholat berjama'ah, santr-santri membaca puji-pujian atau solawat atas Nabi Muhamad SAW. Setelah semua siap, dilanjukan dengan Sholat Subuh berjama'ah.

\section{Perubahan Spiritual}

Menurut Danah Zohar dan Ian Marshall, jika orang cerdas akan spirial, maka orang tersebut bisa menghadapi dan memecahkan persoalan makna dan nilai, yaitu kecerdaan yang dapat menempatkan perilaku dan hidup kita dalam konteks makna yang lebih luas dan kaya, kecerdasan untuk menilai bahwa tindakan atau jalan hidup kita lebih bermakna dibandingkan orang lain. ${ }^{20}$ Cerdas akan spiritual merupakan landasan yang diperlukan untuk memfungsikan intelligensi quotient dan emotional quotient secara efektif. Bahkan, kecerdasan spiritual meru-pakan kecerdasan tertinggi dalam hidup kita. ${ }^{21}$

Untuk meningkatkan spiritual terdapat beberapa langkah, diantaranya adalah dengan berpuasa, shalat jama'ah, membaca al-Qur'an dan berdzikir yang didalamnya terdapat bacaan La illaha illallah atau beristighfar, bertasbih, tahlil, takbir dan tahmid.22 Semua bacaan yang dapat menambah spiritual diatas tecantum dalam bacaan ketika istoghotsah, hususnya di Pondok Pesantren HM Al-Mahrusiyah.

Istighotsah merupakan kegiatan yang didalamnya terdapat unsur berdzikir untuk mendekatkan diri kepada Alloh SWT. Orang yang berdzikir (mengingat Alloh) senantiasa akan merasa dekat dngannya. Kebersamaan atau

20 Danah Zohar dan Ian Marshall, Spiritual Quotient (Bandung: Mizan Media Utama, 2000), h. 4.

21 Zohar dan Marshall, Spiritual kedekatan ini bersifat khusus bukan kebersamaan atau kedekatan sebab bersanding. Hal tersebut dirasakan karena istighotsah merupakan salah satu cara berdo'a untuk mengharapkan pertolongan dengan memasukan unsur kekuasaan Alloh didalamnya. Aspek dalam istighotsah menuntun seseorang untuk mengingat Alloh, ikhlas, pasrah, serta meminta ampunan kepada Alloh.

Dalam istighotsah terdapat banyak sekali faedah-faedah yang terkandung di dalamnya, seperti tanwirul qulub kalo di deskripsikan ketika kita melakukan hal apapun kita hanya memiliki tujuan taqoruban lalloh, bersyukur ketika mendapatkan segala niknat, merasa tercukupi dengan segala yang dimiliki, bersabar ketika mendapatkan cobaan, dan selalu tawakal kepada Alloh.

Kemudian Jalburrizqi, yang dimaksud dengan jalburrizqi disini ialah dipermudah rizqinya. Disini harus kita fahami bahwa yang dimaksud rizqi disini bukan semata untuk harta, akan tetapi rizqi itu ada kalanya berupa uang, adakalanya berupa kesehatan dan adakalanya berupa keselamatan. Dari berbagai macam rizqi, itu semua datang dari Alloh, dan yang terpenting dengan adanya istighotsah yang memiliki salah satu faedah berupa jalbur rizqi, kita selalu merasa qonaah (menerima apa adanya), tidak nggrangsang (ingin memiliki sesuatu yang belum bisa di miliki).

Kemudian faedah perlindungan. Kita selalu terjaga, baik dari ancaman yang terlihat, maupun yang tidak terlihat. Yang dimaksud ancaman terlihat ialah dari sesama manusia ataupun hewan. Kemudian yang tak terlihat dari godaan syetan dan jin. Karena hati kita selalu Istidhor, selalu menghadirkan

22 Abd. Wahab dan Umiarso, Kepemimpinan Pendidikan dan Kecerdasan Spiritual (Jogjakarta: Ar-Ruzz Media, 2011), h. 182-190.

Quotient, h. 4. 
Alloh dengan dzikir-dzikir yang sudah dilaksanakan, maka hati kita akan selalu merasa terlindungi dari godaan syetan.

Kemudian faedah Ghaibah (daya tarik). Harus difahami, yang dimaksud daya tarik disini bukan teruntuk lawan jenis, akan tetapi kehadiran kita itu selalu memancarkan kebaikan yang mempengaruhi dirinya sendiri ataupun orang lain. Pengaruh daya tarik disini selalu mengajak dalam hal kebaikan.

Tidak diragukan lagi, bahwa istighotsah memiliki dampak yang sangat kuat dalam mempengaruhi spiritual seseorang. Hal yang paling dirasakan oleh seseorang ketika rutin mengikuti istighotsah ialah ketenangan dan ketentraman hati setelah melakukan istighotsah, terlebih lagi jika memahami arti yang terkandung dalam syair bacaan istighotsah, terlebih lagi dengan istiqomah.

Banyak sekali manfaat beristighotsah dengan istiqomah, diantaranya menjadi teladan yang baik, orang yang selalu istiqomah dalam berbuat kebaikan seperti istighotsah pastinya akan menjadi orang yang baik. Menjadi orang yang disiplin, seseorang yang istiqomah untuk melakukan istighotsah pasti dia disiplin akan waktu dan tidak pernah telat untuk melakukan sholat berjamaah di masjid khususnya Sholat Shubuh. Mendapatkan pahala, pastinya orang yang beristiqomah untuk melakukan istighotsah mendapatkan pahala yang besar. Dilapangkan rezekinya, seseorang yang selalu beribadah kepada Allah dalam hal ini terhususkan istighotsah, otomatis orang tersebut akan selalu dekat dengan Allah Swt dan Insyaa Allah Allah SWT akan melapangkan rezekinya dan memberkahi rezekinya. Mendapat pertolongan dari Allah SWT, seorang

23 Departemen Agama RI, Al-Qur'an dan Terjemahnya, (Jakarta: Pelita 2012), hal. 252.

24 Tuhfatul Khalidiyah, "Istighotsah Gus

Ali Mustofa Asady Dalam Membangun yang istiqomah beristighotsah pastinya akan dekat dan lebih mengenal dengan Allah Swt, seperti sabda rosululloh, Kenalilah Allah pada waktu lapang, niscaya Allah akan mengenalimu ketika susah". Dalam hadis tersebut berarti jika kita mengenal lebih dekat dengan Allah Swt dan ketika kita susah, maka Allah Swt akan menolongnya. Dan masih banyak lagi manfaat bagi orang yang beristighotsah dengan istikimah.

Artinya: wahai orang-orang yang beriman tentramkanlah hati kalian dengan berdzikir atau mengingat Alloh, ingatlah bahwasannya berdzikir kepada Alloh menentramkan hati. "QS. Ar-Ra'd: 28".23

Ayat diatas menjelask bahwa dengan mengingat Alloh, maka hati akan menjadi tentram. Seperti halnya bacaan dalam istighotsah yang mengandung unsur berdzikir untuk mengingat dan meminta pertolongan pada Alloh.

Tuhfatul Khalidiyah dalan Skripsinya beranggapan, kegiatan istighotsah dapat membangun jiwa kembali tersadarkan, menjadi ingat kepada Alloh SWT, menyesali dosa-dosa yang pernah dilakukan, dan menadikan hati tenang dalam menjalani kehidupan. ${ }^{24}$

\section{Kesimpulan}

Pertama, Istighotsah dilakukan pada jam 02.30 WIB. Kegiatan ini dilakukan dengan tiga tahap: (a) Tahap Pra Istighotsah: Pengurus pondok mengkoordinir santri untuk bergegas menuju ke masjid; (b) Tahap Istighotsah, (1) Muqodimah. Istighotsah diawali dengan melakukan sholat sunat Tasbih sebanyak empat roka'at dengan dua kali salam, sunat Witir sebanyak tiga

Emosional Spiritual Qoutient Pada Siswa Dalam Menghadapi Ujian Nasional di Singosari Kabupaten Malang", (Skripsi, UIN Malang, 2019), h. 145 .

el Bidayah: Journal of Islamic Elementary Education 
raka'at, sholat sunat hajat sebanyak empat roka'at dengan satu kali salam. Setelah selesai melakukan sholat sunat Hajat, imam istighotsah memimpin jama'ah istighotsah untuk membaca surah al-Ikhlas sebanyak $71 x$, kemudian membaca Sholawat sebanyak 71x, kemudian membaca do'a istighfar meminta ampunan sebanyak 71x dan membaca surah al-Fatihah sebanyak 71x. (2) Isi. Pada bagian ini imam istighotsah memimpin bertawasul, kemudian membaca surat Yasin. Diteruskan dengan membaca tahlih beserta wirid-wirid yang terkandung di dalamnya bacaan dzikir. (3) Penutup. Membaca Hisbus Salamah, Hisbun Nasar Lil Istighotsah dan membaca Do'a Fil Istighotsah dan diahiri dengan membaca sholawat atas Nabi Muhammad SAW. Membaca sholawat merupakan bagian akhir dari kegiatan istighotsah di Pondok Pesantren HM Al-Mahrusiyah III Ngampel. (c) Tahap Pasca Istighotsah: Setelah selesai istighotsah, Muadzin mengumandangkan Adzan Shubuh. Dilanjutkan dengan Sholat Subuh berjama'ah. Pelaksanaan Sholat Subuh berjama'ah merupakan akhir dari rangkaian kegiatan istighotsah yang dilakukan di Pondok Pesantren HM Al-Mahrusiyah III Ngampel Kediri.

Kedua, Perubahan spiritual yang dirasakan setelah melakukan istighotsah. Ada dua perubahan spiritual yang dirasakan setelah melakukan istighotsah yakni dari dhohir dan batin, (a) Perubahan secara batin: setelah mengikuti istighotsah setiap hari, para santri memiliki rasa semangat dalam melakukan aktifitas sehari-hari seperi sekolah Formal maupun Diniyyah. Mereka mera- sakan rasa emosi menjadi berkurang serta bisa membagi waktu. (b) Perubahan Batin: para santri merasakan tenang hatinya, merasakan lebih dekat dengan Alloh, merasakan ada penyemangat dalam melakukan hal kebaikan dan merasakan ada yang melarang ketika akan berbuat kejelekan.

\section{Daftar Pustaka}

Abd al-Halīm Mahmūd Ali, Al-Tarbìyah al-Rūhīyah, (Qāhirah: Dār alTauzī' wa al-Nasyr al-Islāmiyah, 1995).

Afrizal, Wawancara, Kelas Pondok Pesantren HM Al-Mahrusiyah III Ngampel, 12 Juli 2020.

Asif Muhamad Fadli Zamzami, Wawancara, Pengurus Jami'iyah Pondok Pesantren HM AlMahrusiyah, 5 Juli 2020.

Ayyam Sayidul, Wawancara, Kantor Pondok Pesantren HM AlMahrusiyah III Ngampel, 15 Juli 2020.

Dali Zulkarnain, "Menejemen Mutu Pondok Pesantran", At-Ta'lim, Vol. 12, No. 1, (Januari 2013).

Daud Ali Muhamad, Pendidikan Agama Islam (Jakarta: PT. Raja Grafindo, 2002).

Djumaransjah Muhamad dan abdul Malik Karim Amrulloh, Pendidikan Islam , Menggali Tradisi, Meneguhkan eksistensi, (Malang: UIN Malang Perss, 2007).

Dzaky, Wawancara, Santri Pondok Pesantren Lirboyo HM. AlMahrusiyah, 10 Juni 2020.

Fauzi, Fuad. "Pendidikan Spiritual Dalam Mengembangkan Karakter Perspektif Imam AlGozali." Universitas Islam Negeri Sunan Kalijaga, 2015. 
Firman, Wawancara, Santri Pondok Pesantren Lirboyo HM. AlMahrusiyah, 10 Juni 2020.

Firza, Wawancara, Kantor Pondok Pesantren HM Al-Mahrusiyah III Ngampel, 25 Juli 2020.

Fuad, A. Jauhar "Tlatah Dan Tradisi Keagamaan Islam Mataraman," Jurnal Pemikiran Keislaman 30, no. 1 (January 31, 2019): 1-27, https://doi.org/10.33367/tribak ti.v30i1.659

Hafs Kholid, Wawancara, Kamar Anak Ndalem, Pondok Pesantren Lirboyo HM. Al-Mahrusiyah, 10 Juli 2020.

Hawwa Said, Pendidikan Spiritual (Yogyakarta: Mitra Pustaka, November, 2006).

J. Moleong Lexy, Metodologi Penelitian Kualitatif (Bandung: Remaja Rosda Karya, 2002).

Jadid Nurul, Tujuan Santri, www.NurulJadid.net, diakses tanggal 20 Desember 2019.

Jejak Pendidikan. "Pengertian Pendidikan Spiritual," Desember 2016.

http://www.jejakpendidikan.co $\mathrm{m} / 2016 / 12$ /pengertianpendidikan-spiritual.html.

Khalidiyah Tuhfatul, "Istighotsah Gus Ali Mustofa Asady Dalam Membangun Emosional Spiritual Qoutient Pada Siswa Dalam Menghadapi Ujian Nasional di Singosari Kabupaten Malang", (Skripsi, UIN Malang, 2019).

Khoerudin Arif, Wawancara, Kantor Pondok Pesantren HM AlMahrusiyah III Ngampel, 15 Juli 2020.

Khoerul Anam Muhamad, Wawancara, Kamar Timur Pondok Pesantren Al-Mahrusiyah III Ngampel, 15 Juli 2020.

Kholid Afandi Muhamad Dkk, Pedoman ke-NU-an Kurikulum Madrasah
Hidayatul Mubtadi-in Lirboyo (Kediri: Lembaga Bahtsul Masail, 2014).

Lubis Khoerudin. "Pembinaan Mental Spiritual Santri di Pesantren Modern Unggulan Terpadu Darul Mursyid Kabupaten Tapanuli Selatan." Analitica Islamica 7 (2018).

Ma'sum Ishomudin, Sejarah dan Keutamaan Istighotsah (Surabaya: PWLTN NU Jawa Timur/LTN Pustaka, 2018).

Mohana, Wawancara, Mustahiq di Pondok Pesantren AlMahrusiyah III Ngampel, 4 Juli 2020.

Muhamad "Pendidikan Spiritual Santri Dalam Membaca al-Qur'an Pondok Pesantren Haji Mahrus (PPHM) Lirboyo Kediri." (Skripsi, IAIT Kediri, 2017).

Mulyana Dedy, Metodologi Penelitian Kualitatif (Bandung: PT. Remaja Rosdakarya, 2010).

Nafiul Karim Muhamad. "Pendidikan Spiritual Santri Dalam Membaca Al-Qur'an di Pondok Pesantren Haji Mahrus Lirboyo Kota Kediri." IAI Tribakti, 2017.

Najmudin Ahmad, Wawancara, Kantor Pondok Pesantren HM AlMahrusiyah III Ngampel, 15 Juli 2020.

Rafli, Wawancara, Santri Pondok Pesantren Lirboyo HM. AlMahrusiyah, 10 Juni 2020.

Satiadarma Montay P dan Fidelis E. Waruwu, Mendidik Kecerasan (Jakarta: Pustaka Populer Obor, 2003).

Susanto Happy. "Perubahan Perilaku Santri." Journal of Universitas Muhammadiyah Ponorogo 2 (2016).

Susilo Suko, Metode Penelitian Kualitatif (Surabaya: Jenggala Pustaka Utama, 2013). 